\title{
Can FDI Be an Engine of Economic Diversification in A Small Open Economy: The Case of Macau
}

\author{
ChunLi JI \\ Gaming Teaching and Research Centre, Macao Polytechnic Institute, Macao \\ Business school, Yunnan University of Finance and Economics, China
}

\begin{abstract}
Taken Macau as an example, we uses the Grey Relational Analysis method to explore the effects of FDI on economic diversification depended on a time series dataset from 2002 to 2013. Results show that in small open economies (Macau as an example), FDI is negatively correlated to the economic diversification. This conclusion is different from the result got in some previous studies.
\end{abstract}

KEYWORD: FDI; Economic diversification; Small open economy

\section{INTRODUCTION}

In the last two decades, foreign direct investment (FDI) flows have grown rapidly all over the world and also play a significant role in an economy. While relatively few studies have explicitly considered the impact of FDI-related diversification effects on economy. Recently, a handful of studies that directly address the link between FDI and export diversification have started to emerge (Tadesse and Shukralla, 2013 [1]). Many previous researches argued that FDI is the key factor in speeding up both the vertical and horizontal diversification of exports (e.g., Yokoyama and Alemu, 2009 [2]). However, for nations that export a high proportion of oil and mineral resources, Jayaweera (2009) finds a negative association implying that the effect of FDI on export diversification is sensitive to the mix of products exported by a country.[3] These findings indicate that the effect of FDI on export diversification is not robust to sample composition, reference period and the econometric specification used. At the same time, few studies have examined the relationship between economic diversification and FDI directly (Tadesse and Shukralla, 2013 [1]). Also, findings from the various cross-sectional studies on the relationship between FDI and export diversification cannot be generalized. There is need for country specific studies on the subject matter to shed more light on the debate and allow for more country specific policies. Using the case study of Macau, this paper contributes to the literature by illustrating the effect of FDI on economic diversification in a small open economy.

\section{BACKGROUND: MACAU AS A TYPICAL SMALL OPEN ECONOMY}

Macau is a Special Administrative Region (SAR) of the People's Republic of China. Under the "one country, two systems" formula, Macau enjoys a "high degree of autonomy" in all matters except foreign affairs and defense. With a population of about 607,500 , a land area of $28.2 \mathrm{~km} 2$ and a GDP value of about USD51.68 billion at the end of 2013, Macau is a typical small open economy. It is keen on attracting foreign capital to build up its own economy. According to the direct investment statistics released by the Statistics and Census Service (DSEC) of Macau, the FDI was only MOP 1.3 billion in 2001, but at the end of 2013, FDI coming into Macau amounted to MOP 36.1 billion in 2013. With the soaring of FDI, however, Macau's recent strong economic growth has been concentrated in the tourism sector, mainly related to the gaming industry. How to diversify its economy is a huge challenge for Macau Government.

\section{DATA AND METHODOLOGY}

The main purpose of this paper is to explore the relationship between FDI and economic diversification in Macau. Following Smith and Gibson (1988) [4], the entropy index is used to measure economic diversification. The entropy index (EI) of economic diversity (X0) can be defined as follows:

$$
E I=\sum_{i=1}^{n} S_{i} \ln \left(\frac{1}{S_{i}}\right)
$$


Where $\mathrm{n}$ is the number of sectors, $\mathrm{Si}$ is share of economic activity in ith industry and $\ln$ is natural logarithm. Higher entropy index values indicate greater relative diversification, while lower values indicate relatively more specialization. FDI is measured as foreign direct investment stock (X1). In order to find out whether FDI is the most important factor that affects the economic diversification, the paper also includes a number of other variables, including GDP per capita (X2), employment population (X3), an index of trade openness (X4) calculated as the total volume of trade(export +import)divided by GDP, gross fixed capital formation (X5). All of these variables have been found correlated with the level of diversification in previous studies. DSEC of Macau provides data of all variables. We collected yearly figures from 2002 to 2013.

Due to the limitation of sample size, grey relational analysis (GRA) was conducted to examine the correlation among the variables. GRA derived from grey system theory proposed by J.L. Deng, which is one of the new mathematical theories born out of the concept of the grey set(Deng,1982 [5]). The Grey System Theory does not have sample size limitations, and thus the GRA is used to verify
Pearson's analysis results. The mathematics of the GRA is as follows:

(1) Data processing $\mathrm{Xi}(\mathrm{k})=(\mathrm{X}(1), \mathrm{X}(2), \ldots, \mathrm{X}$ (k)) to establish each data series.

In order for the series to be comparable for GRA, "Grey Relation Generating" must be used. Grey Relation Generating is categorized into the following three kinds:

(a)The greater the better:

$$
X_{i}^{*}(k)=\frac{X_{i}(k)-\min X_{i}(k)}{\max X_{i}(k)-\min X_{i}(k)}
$$

(b)The small the better:

$$
X_{i}^{*}(k)=\frac{\max X_{i}(k)-X_{i}(k)}{\max X_{i}(k)-\min X_{i}(k)}
$$

(c)The close to the target the better

$$
X_{i}^{*}(k)=1 \frac{X_{i}(k)-O B}{\max \left[\max X_{i}(k)-O B_{3} O B-\min X_{i}(k)\right]}
$$

In this paper, we use (a) the greater the better and (b) the smaller the better for the sequence, and the results are shown in Table1.

Table 1.Grey relation generating results

\begin{tabular}{|c|c|c|c|c|c|c|c|c|c|c|c|}
\hline \multicolumn{9}{|c}{ The greater the better } & \multicolumn{9}{c|}{ The small the better } \\
\hline $\mathrm{X} 0$ & $\mathrm{X} 1$ & $\mathrm{X} 2$ & $\mathrm{X} 3$ & $\mathrm{X} 4$ & $\mathrm{X} 5$ & $\mathrm{X} 0$ & $\mathrm{X} 1$ & $\mathrm{X} 2$ & $\mathrm{X} 3$ & $\mathrm{X} 4$ & $\mathrm{X} 5$ \\
\hline 0.810 & 0.000 & 0.000 & 0.000 & 0.946 & 0.000 & 0.190 & 1.000 & 1.000 & 1.000 & 0.054 & 1.000 \\
\hline 1.000 & 0.016 & 0.025 & 0.003 & 1.000 & 0.100 & 0.000 & 0.984 & 0.975 & 0.997 & 0.000 & 0.900 \\
\hline 0.990 & 0.032 & 0.091 & 0.092 & 0.924 & 0.216 & 0.010 & 0.968 & 0.909 & 0.909 & 0.077 & 0.784 \\
\hline 0.977 & 0.088 & 0.123 & 0.209 & 0.405 & 0.479 & 0.023 & 0.912 & 0.877 & 0.791 & 0.595 & 0.521 \\
\hline 0.790 & 0.167 & 0.186 & 0.379 & 0.233 & 0.767 & 0.210 & 0.833 & 0.814 & 0.621 & 0.767 & 0.233 \\
\hline 0.310 & 0.290 & 0.264 & 0.566 & 0.481 & 1.000 & 0.690 & 0.710 & 0.736 & 0.434 & 0.519 & 0.000 \\
\hline 0.304 & 0.356 & 0.315 & 0.719 & 0.510 & 0.822 & 0.696 & 0.644 & 0.685 & 0.281 & 0.490 & 0.178 \\
\hline 0.471 & 0.356 & 0.332 & 0.681 & 0.000 & 0.490 & 0.529 & 0.644 & 0.668 & 0.319 & 1.000 & 0.510 \\
\hline 0.513 & 0.509 & 0.517 & 0.704 & 0.371 & 0.373 & 0.487 & 0.491 & 0.483 & 0.296 & 0.629 & 0.627 \\
\hline 0.292 & 0.571 & 0.714 & 0.783 & 0.664 & 0.471 & 0.708 & 0.429 & 0.286 & 0.217 & 0.337 & 0.529 \\
\hline 0.000 & 0.780 & 0.835 & 0.884 & 0.492 & 0.605 & 1.000 & 0.221 & 0.165 & 0.116 & 0.508 & 0.395 \\
\hline 0.023 & 1.000 & 1.000 & 1.000 & 0.272 & 0.643 & 0.977 & 0.000 & 0.000 & 0.000 & 0.728 & 0.357 \\
\hline
\end{tabular}

(2)Calculate the factor difference $\Delta 0 \mathrm{j}=\| \mathrm{X} 0(\mathrm{k})$ $\mathrm{Xi}(\mathrm{k}) \|, \mathrm{j}=1,2, \ldots, \mathrm{m}, \mathrm{k}=1,2, \ldots, \mathrm{n}$. The factor difference in each series is presented in Table2. It was found that using "the greater the better" and "the small the better" produced the same factor differences, so we just report the result of "the greater the better".

(3)Finding the max difference and min difference

$$
\begin{gathered}
\Delta_{\mathrm{nax}}=\min _{j} \min _{k}\left\|X_{0}(k)-X_{j}(k)\right\|_{\min }=\min _{j} \min _{k}\left\|X_{0}(k)-X_{j}(k)\right\| \\
\Delta_{\max }=\min _{j} \min _{k}\left\|X_{0}(k)-X_{j}(k)\right\|
\end{gathered}
$$

(4) Setting the identification coefficient $\zeta$ (between 0 and 1) according to actual needs. $\zeta$ is the distinguishing factor to control the resolution between $\Delta \max$ and $\Delta \min$ and often sets 0.5 . The $\zeta$ value in this empirical study is also set as 0.5 .

(5)Finding the grey relational coefficient

$$
r\left(X_{0}, X_{i}\right)=\frac{1}{n} \sum_{k=1}^{n} r\left(X_{0}(k), X_{i}(k)\right) r\left(X_{0}(k), X_{i}(k)\right)=\frac{\Delta_{\min }+\zeta_{\max }}{\Delta_{0}(k)+\zeta \Delta_{\max }}
$$

(6)Finding the grey relational grade

$$
r\left(X_{0}, X_{j}\right)=\frac{1}{n} \sum_{k \alpha}^{n} r\left(X_{0}(k), X_{j}(k)\right)
$$


Table 2.The factor difference in each series

\begin{tabular}{|c|c|c|c|c|c|}
\hline \multicolumn{6}{|c|}{ The greater the better } \\
\hline Item & $\Delta 01$ & $\Delta 02$ & $\Delta 03$ & $\Delta 04$ & $\Delta 05$ \\
\hline $\mathrm{k}=1$ & 0.8098 & 0.8098 & 0.8098 & 0.1362 & 0.8098 \\
\hline $\mathrm{k}=2$ & 0.9841 & 0.9747 & 0.9974 & 0 & 0.9003 \\
\hline $\mathrm{k}=3$ & 0.9579 & 0.8995 & 0.8988 & 0.0668 & 0.7747 \\
\hline $\mathrm{k}=4$ & 0.889 & 0.854 & 0.7684 & 0.5718 & 0.4978 \\
\hline $\mathrm{k}=5$ & 0.6236 & 0.6046 & 0.4109 & 0.557 & 0.0233 \\
\hline $\mathrm{k}=6$ & 0.0202 & 0.0466 & 0.2552 & 0.1709 & 0.6896 \\
\hline $\mathrm{k}=7$ & 0.0516 & 0.011 & 0.4147 & 0.2059 & 0.5172 \\
\hline $\mathrm{k}=8$ & 0.1151 & 0.1385 & 0.2105 & 0.4709 & 0.0188 \\
\hline $\mathrm{k}=9$ & 0.0044 & 0.004 & 0.1914 & 0.1421 & 0.1402 \\
\hline $\mathrm{k}=10$ & 0.2796 & 0.4224 & 0.4915 & 0.3719 & 0.179 \\
\hline $\mathrm{k}=11$ & 0.7795 & 0.8348 & 0.8836 & 0.492 & 0.605 \\
\hline $\mathrm{k}=12$ & 0.9767 & 0.9767 & 0.9767 & 0.2483 & 0.6194 \\
\hline Max & 0.9841 & 0.9767 & 0.9974 & 0.5718 & 0.9003 \\
\hline Min & 0.0044 & 0.004 & 0.1914 & 0 & 0.0188 \\
\hline
\end{tabular}

Table 3.The grey relational coefficients

\begin{tabular}{|c|c|c|c|c|c|}
\hline Item & $\Delta 01$ & $\Delta 02$ & $\Delta 03$ & $\Delta 04$ & $\Delta 05$ \\
\hline $\mathrm{k}=1$ & 0.3811 & 0.3811 & 0.3811 & 0.7855 & 0.3811 \\
\hline $\mathrm{k}=2$ & 0.3363 & 0.3385 & 0.3333 & 1.0000 & 0.3565 \\
\hline $\mathrm{k}=3$ & 0.3424 & 0.3567 & 0.3569 & 0.8819 & 0.3916 \\
\hline $\mathrm{k}=4$ & 0.3594 & 0.3687 & 0.3936 & 0.4659 & 0.5005 \\
\hline $\mathrm{k}=5$ & 0.4444 & 0.4520 & 0.5483 & 0.4724 & 0.9554 \\
\hline $\mathrm{k}=6$ & 0.9611 & 0.9145 & 0.6615 & 0.7448 & 0.4197 \\
\hline $\mathrm{k}=7$ & 0.9062 & 0.9784 & 0.5460 & 0.7078 & 0.4909 \\
\hline $\mathrm{k}=8$ & 0.8125 & 0.7826 & 0.7032 & 0.5143 & 0.9637 \\
\hline $\mathrm{k}=9$ & 0.9913 & 0.9920 & 0.7226 & 0.7782 & 0.7806 \\
\hline $\mathrm{k}=10$ & 0.6408 & 0.5414 & 0.5036 & 0.5728 & 0.7359 \\
\hline $\mathrm{k}=11$ & 0.3902 & 0.3740 & 0.3608 & 0.5034 & 0.4518 \\
\hline $\mathrm{k}=12$ & 0.3380 & 0.3380 & 0.3380 & 0.6676 & 0.4460 \\
\hline Grey relational grade & 0.5879 & 0.5820 & 0.4932 & 0.6829 & 0.5853 \\
\hline
\end{tabular}

The grey relational grade is the average grey relational coefficient in each series(in Table 3).

(7)Finding the grey relational order

According to the average grey relational coefficient of each sequence in Table 3 , we can get the rankings of the grey relational grades: $\mathrm{X} 4>\mathrm{X} 1>\mathrm{X} 5>\mathrm{X} 2>\mathrm{X} 3$.

\section{GREY RELATIONAL ANALYSIS-POLARITY ANALYSIS}

The grey relational order can only reflect the important factors that affect the target value, and not the polarity of the relationship. Fu(1992) provided the following methods to distinguish factor relation characteristics.[6] The $\sigma_{\mathrm{k}}$ and $\sigma_{\mathrm{i}}$ are defined as:

$$
\begin{aligned}
& \sigma_{k}=\sum_{k=1}^{n} k^{2}-\left(\sum_{k=1}^{n} k\right)^{2} / n \\
& \sigma_{i}=\sum_{i=1}^{n} k X_{i}(k)-\sum_{i=1}^{n} X_{i}(k) \sum_{k=1}^{n} k / n
\end{aligned}
$$

If sgn $\left(\sigma_{\mathrm{i}} / \sigma_{\mathrm{k}}\right)=\operatorname{sgn}\left(\sigma_{\mathrm{j}} / \sigma_{\mathrm{k}}\right)$ where sgn is a symbol function, then $\mathrm{Xi}$ and $\mathrm{Xj}$ are positively related. If sgn $\left(\sigma_{\mathrm{i}} / \sigma_{\mathrm{k}}\right)=-\operatorname{sgn}\left(\sigma_{\mathrm{j}} / \sigma_{\mathrm{k}}\right)$, then $\mathrm{Xi}$ and $\mathrm{Xj}$ are negatively related. According to above equations, the values of $\sigma_{\mathrm{i}}$ and $\sigma_{\mathrm{k}}$ for each variable are presented in table 4 . 
Table 4.Grey Relational Analysis-Polarity Analysis Results

\begin{tabular}{|c|c|c|c|c|c|c|}
\hline Item & $\mathrm{X} 0$ & $\mathrm{X} 1$ & $\mathrm{X} 2$ & $\mathrm{X} 3$ & $\mathrm{X} 4$ & $\mathrm{X} 5$ \\
\hline$\sigma_{\mathrm{k}}$ & 143 & 143 & 143 & 143 & 143 & 143 \\
\hline$\sigma_{\mathrm{i}}$ & -1.14 & 1993025 & 7144450 & 2134.2 & -237 & 341787 \\
\hline Correlation to FDI(X0) & & $\mathrm{NC}$ & $\mathrm{NC}$ & $\mathrm{NC}$ & $\mathrm{PC}$ & $\mathrm{NC}$ \\
\hline
\end{tabular}

Note: NC means negative correlation; PC means positive correlation

\section{CONCLUSIONS AND DISCUSSIONS}

This paper uses the GRA method to explore the relationship among economic diversification, FDI and some other economic variables. Results show that in small open economies (Macau as an example), FDI is negatively correlated to the economic diversification At the same time, FDI has higher level of negative relation to economic diversification than some other economic variables (excluding trade openness). However, many previous researches argue that FDI plays an important positive role in the economic diversification strategy because of the multiplier effect it had on job creation and spillover effect of intellectual capital and technology. Due to the different economy aspects between open small economies and large economies, this finding contributes to the literature by illustrating the effect of FDI on economic diversification and policymakers of a small open economy can make some strategic implications up to the relationship of FDI on economic diversification.

\section{ACKNOWLEDGEMENTS}

This work was supported by National Natural Science Foundation of China (Nos. 71462034; 71462035). MPI-funded research project(RP/OTHER-02/2013).

\section{REFERENCES}

[1] Tadesse, B., Shukralla E. K., The impact of foreign direct investment on horizontal export diversification: Empirical evidence. Applied Economics45:141-159.

[2] Yokoyama, K., A. M. Alemu, 2009. The impacts of vertical and horizontal export diversification on growth between Sub-Saharan Africa and East Asia's Performances. Ritsumeikan International Affairs7 (3): 4990.

[3] Jayaweera, S., 2009. Foreign direct investment and export diversification in low income nation. Thesis, The University of New South Wales.

[4] Smith, S. M., C. S. Gibson., 1988. Industrial diversification in nonmetropolitan counties and its effect on economic stability. Western Journal of Agricultural Economics 13: 193-201.

[5] Deng, J. L.,1982. Control problem of grey system. System \&Control Letters 5: 288-294.

[6] Fu, L., 1992. The Grey System Theory and Its application, Beijing, STDPH . 